\title{
OS JARDINS DA RESIDÊNCIA MOREIRA SALLES O PROJETO ORIGINAL DE BURLE MARX E A RESTAURAÇÃO DE ISABEL DUPRAT
}

\author{
SANTOS, Eloisa \\ Paisagista pela EBA-UFRJ, Especialista em História da Arte e Arquitetura no Brasil pela PUC-RJ e Mestre \\ pelo PROARQ/FAU/UFRJ. E-mail: elosantos@terra.com.br
}

\section{RESUMO}

Esse artigo se propõe a uma análise morfológica com base nas linhas projetuais paisagísticas para a residência Moreira Salles, atual centro cultural Instituto Moreira Salles, localizada no bairro da Gávea, no Rio de Janeiro, e projetada em 1950 pelo arquiteto Olavo Redig de Campos. Através do estudo comparativo entre o projeto do paisagista Roberto Burle Marx, concebido um ano depois, e o de restauração, elaborado pela paisagista Isabel Duprat e concluído em 1999, podemos identificar as influências reveladas pelo projeto original, a relação dos jardins de Burle Marx com uma edificação representativa da Arquitetura Moderna, e as mudanças ocorridas nesse espaço ao longo de quase meio século.

Palavras-chave: Residência Moreira Salles, projeto paisagístico original de Burle Marx, restauro de Isabel Duprat.

\begin{abstract}
This article consists of a morfologic analysis of the projected landscape of the residence of Moreira Salles, the current cultural center of the Institute of Moreira Salles, located in the neighborhood of Gávea, in Rio de Janeiro, designed in 1950 by architect Olavo Redig de Campos. By a comparative study between the project of landscape designer Roberto Burle Marx, conceived one year later, and the restoration, elaborated by the landscape designer Isabel Duprat and concluded in 1999, we can identify the influences revealed by the original project, the relation of the gardens of Burle Marx with a building representative of Modern Architecture, and the changes that have occurred in this space over close to a half a century.
\end{abstract}

Key words: The residence of Moreira Salles - an original landscape project of Burle Marx, restored by Isabel Duprat.

\section{Introdução}

O conhecimento das intenções paisagísticas originais para a residência Moreira Salles (edificação residencial uni-familiar, projetada em 1950, na escala horizontal, atual centro cultural Instituto Moreira Salles, no Rio de Janeiro) foi possibilitado pelo único material gráfico cedido pelo escritório Burle Marx e Cia. Ltda., planta $n^{\circ} 95$, em atendimento à solicitação da arquiteta paisagista Isabel Duprat, que o utilizou como base para a elaboração do projeto de recuperação do paisagismo daquele espaço, concluído em março de 1999. Para uma análise comparativa entre o tratamento paisagístico original e o atual, objeto desse artigo, além desse material, Isabel Duprat disponibilizou uma planta do seu projeto de restauração, também em cópia vegetal. Fotografias em periódicos ajudaram a suprir a precariedade de indicações do desenho do projeto original, como, por exemplo, as que se referem à vegetação utilizada e ao material empregado na pavimentação.'

Os jardins da residência Moreira Salles, ocupando uma área de $7.800 m^{2} 2$, tiveram incluídos três espelhos d'água em seu projeto original: a piscina / o lago em frente a um painel de azulejos / e um pequeno lago, em frente a um dos quartos da ala íntima, que dá para a área da piscina ${ }^{c 3}$. 
Quatro áreas foram destacadas para nossa análise, cujo critério de setorização considerou as que apresentavam simultaneamente características distintas e estabeleciam um diálogo diferenciado com a arquitetura. A vegetação, o piso, e os elementos construídos foram fatores determinantes para essa escolha, que compreendeu:

- jardim frontal

- jardim geométrico

- pátio interno

- área da piscina

O jardim frontal, a área da piscina e o pátio interno são caracterizados pelo uso das formas orgânicas, sugerindo que o tratamento paisagístico se contrapõe à geometrização predominante da arquitetura, ao contrário do jardim geométrico que parece reforçar essa rigidez formal.

\section{Análise morfológica dos espaços}

\section{Jardim frontal}

A espacialidade como um todo se apresenta "fechada", configurando-se como um vale, devido à proximidade dos morros e à intensa vegetação de mata atlântica circundante. Esse "fechamento" se acentua com a proximidade entre as muitas espécies vegetais de grande porte, como é o caso do jardim frontal, onde, segundo Duprat, no projeto original realizado por Burle Marx (Fig.1), foi determinada a utilização de vegetação de sombra para a área, demandando apenas a indicação de um pequeno número de novas espécies.

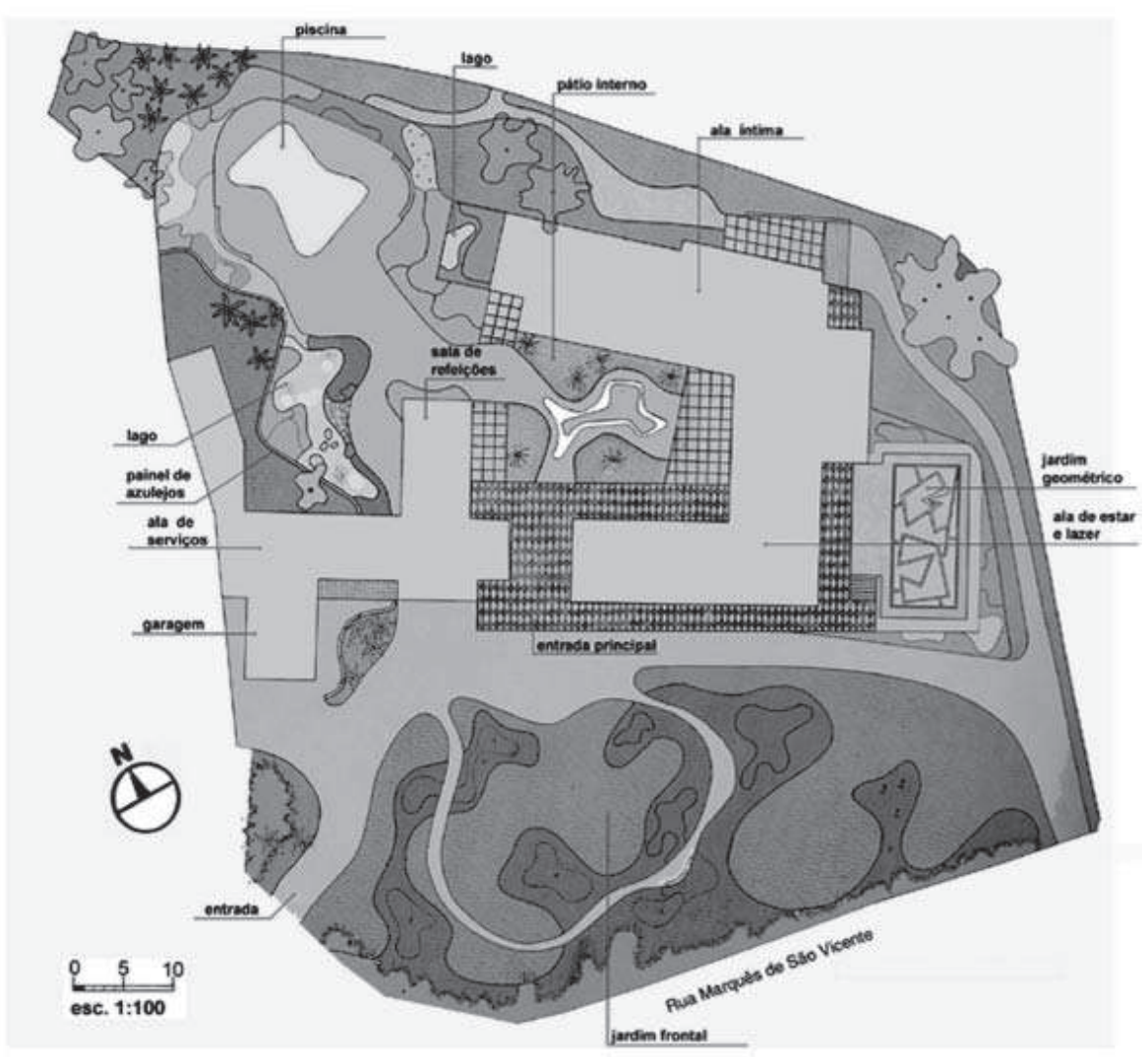

Figura 1: Planta geral do projeto oiginal sem indicação da vegetação - onde podemos observar as linhas geométricas da arquitetura (em rosa) e a setorização da área que recebeu o tratamento paisagístico.

Fonte: Cópia do desenho em vegetal, com indicação das espécies vegetais, cedida por Isabel Duprat, em 2003, colorida pela autora para facilitar a leitura da proposta como um todo 
O projeto original criou amplos espaços de passeio para o jardim frontal, com caminhos ladeados por canteiros com vegetação arbustiva e rasteira distribuídas de maneira a formarem setores de contornos de linhas orgânicas.

Na listagem da vegetação total constante do Projeto de Recuperação, observamos uma quantidade significativa de frutíferas no Jardim Frontal, cujo porte indica que são remanescentes do projeto original. Muitas dessas árvores, dentre elas a jaqueira, o jambeiro, o abacateiro, que junto a outras de grande altura, atuam como protetoras visuais em relação ao exterior urbano, ao mesmo tempo em que, ao promoverem amplas áreas sombreadas, integram esse espaço à mata atlântica circundante. Porém, essa massa vegetativa, separada da edificação por um largo passeio em pedras, em nada interfere na apreensão do objeto arquitetônico, como mostra a Fig. 1. Próximo à edificação, ao limitar-se ao plantio de vegetação de baixo porte junto à parede em pedras do guarda-corpo do corredor externo, em piso de mármore, o paisagismo revela que privilegiou o destaque da arquitetura.

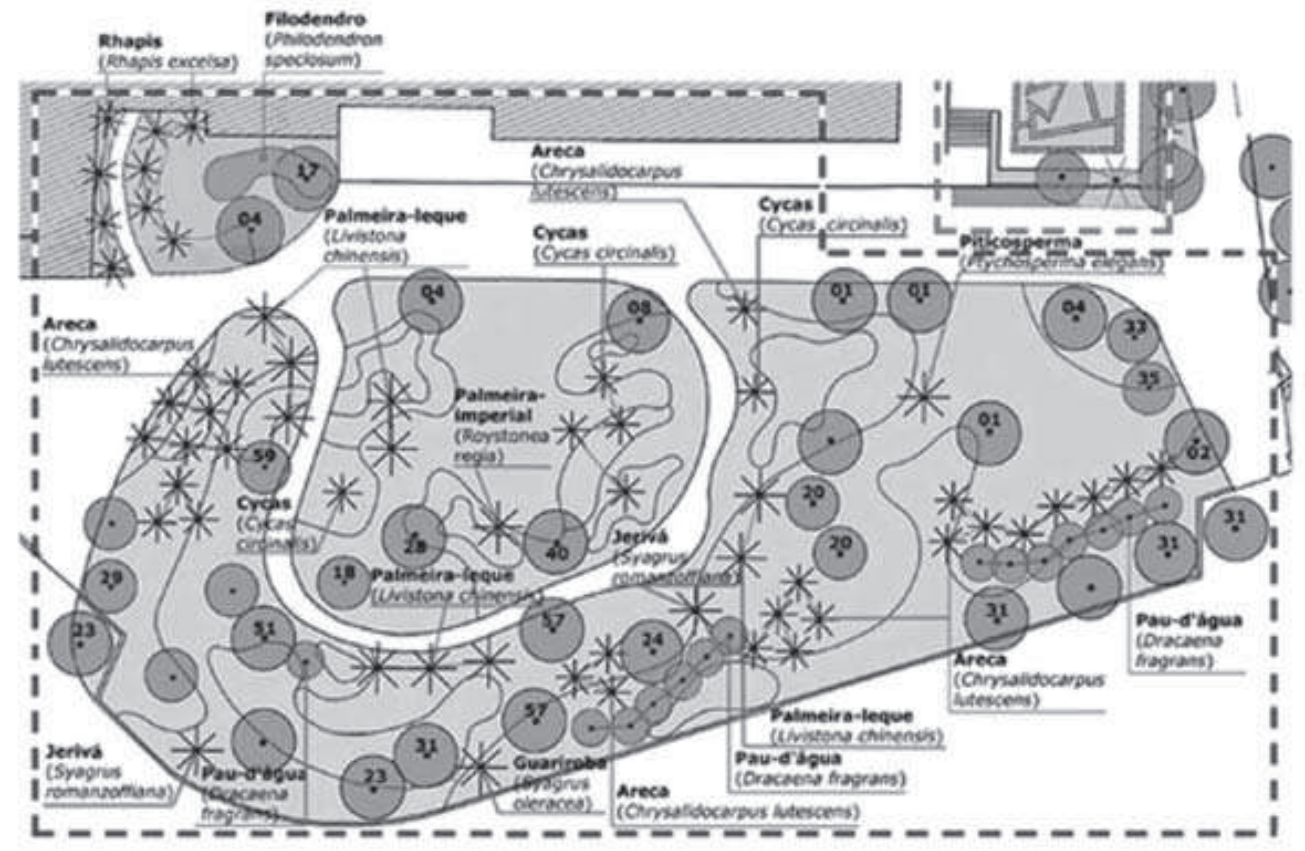

Figura 2: Planta de restauração do jardim frontal - Desenho indicativo das árvores e palmeiras.

Fonte: Desenho resultante de modificações gráficas e coloração pela autora, sobre cópia em vegetal de parte do projeto de restauração elaborado por Isabel Duprat

\section{Listagem das árvores indicadas no projeto de restauração do jardim frontal}

\begin{tabular}{l|l}
\hline 01. Artocarpus heterephyllus (Jaqueira) & 28. Hymenaea courbaril (Jatobá) \\
\hline 02. Tabebuia sp (Ipê-rosa) & 29. Inga uruguensis (Ingá) \\
\hline 04. Syzygium malaccense (Jambo) & 31. Licania tomentosa (Oiti) \\
\hline 08. Persea americana (Abacateiro) & 33. Stifftia crysantha (Esponja) \\
\hline 17. Plumeria rubra (Jasmim-manga) & 35. Citrus sp (Mixirica) \\
\hline 18. Tabebuia chrysotricha (Ipê-amarelo) & 40. Lecythis pisonis (Sapucaia) \\
\hline 20. Courupita guianensis & 51. Howenis dulces (Rovenia) \\
\hline 23. Caesricó-de-macaco) & \\
\hline 24. Delonix regia (Flamboyant) & 57. Diospyros discolor (Pêssego-da-Índia) \\
\hline
\end{tabular}




\title{
Listagem das plantas arbustivas e de forração indicadas no projeto de restau- ração do jardim frontal
}

\author{
Arbustos \\ - Philodendron speciosum (Filodendro) \\ - Monstera deliciosa (Monstera) \\ - Dichorisandra thyrsiflora (Gengibre-azul) \\ - Bambusa vulgaris (Bambu-verde e amarelo)
}

Plantas de forração

\begin{tabular}{l|l}
\hline 01. Scindapsus aureus (Jibóia) & 25. Calathea makoyana (Calatéia) \\
\hline 06. Curculigo capitulata (Capim-palmeira) & 26. Solanum violaefolium (Solano-rasteiro) \\
\hline 08. Ophiopogon japonicus (Pêlo-de-urso) & 27. Aspidistra elatior (Aspidistra) \\
\hline $\begin{array}{l}\text { 12. Axonopus compressus } \\
\text { (Grama-São Carlos) }\end{array}$ & 28. Tradescantia pallida (Setcresea) \\
\hline 14. Davalia fejeensis (Renda-portuguesa) & 30. Xanthosoma lindenii (Yantia) \\
\hline $\begin{array}{l}\text { 15. Calathea louisae (Calatéia) } \\
\text { 17. Spathiphyllum cannaefolium } \\
\text { (Lírio-da-paz) }\end{array}$ & $\begin{array}{l}\text { 31. Pilea nummularifolia } \\
\text { (Dinheiro-em-penca) }\end{array}$ \\
\hline
\end{tabular}

O tratamento formal com a vegetação de forração e o traçado do pequeno passeio do Jardim Frontal sugere uma releitura do Jardim Inglês. Essa estrutura do jardim original foi mantida no projeto de reestruturação.

\section{Jardim geométrico}

O Jardim Geométrico está localizado num nível abaixo das três outras áreas destacadas para nossa análise. O acesso a ele se dá por uma pequena escada (Fig. 1 e 3) no final do piso de mármore da entrada principal, cuja padronagem é composta por losangos de duas cores (branca e rosada), que se prolonga pela área externa contornando os cômodos que compõem a ala de estar e lazer. Por não se integrar a qualquer outra área, apresentando-se totalmente estanque, poderíamos até dizer que o jardim geométrico teria sido um capricho do paisagista, configurando-se mais como elemento de um espaço e não propriamente como um espaço.

A predominância do enviezamento das "aléias" na escala desse pequeno jardim, com a utilização de espécies vegetais tropicais de colorido intenso (como é o caso dos coleus e acalifas), e onde Burle Marx privilegiou a bi-dimensionalidade, reforça a configuração desse pequeno espaço como alegoria referenciada ao jardim geométrico francês. Porém, como a alegoria não caracteriza o Movimento Moderno, ao contrário do binômio forma / função, o jardim geométrico afastando-se desse cânone do modernismo apresenta-se apenas como um exercício lúdico do paisagista, de influência cubista. De certo modo, esse isolamento parece contrariar o critério estabelecido anteriormente, que considerou o jardim geométrico como "área" a ser destacada pelo diálogo que estabelece com a arquitetura, e poderíamos dizer que a coerência dessa escolha estaria justamente na negação de uma interação com ela. Por outro lado, se abandonarmos a idéia da alegoria, o jardim geométrico configura-se como manifestação do Modernismo, tal qual as experiências geométricas jardinistas de Paul Véra ${ }^{\mathrm{d} 4}$, sendo uma variação da transposição do pictórico cubista para o jardim, uma das marcas do repertório paisagístico de Burle Marx. 


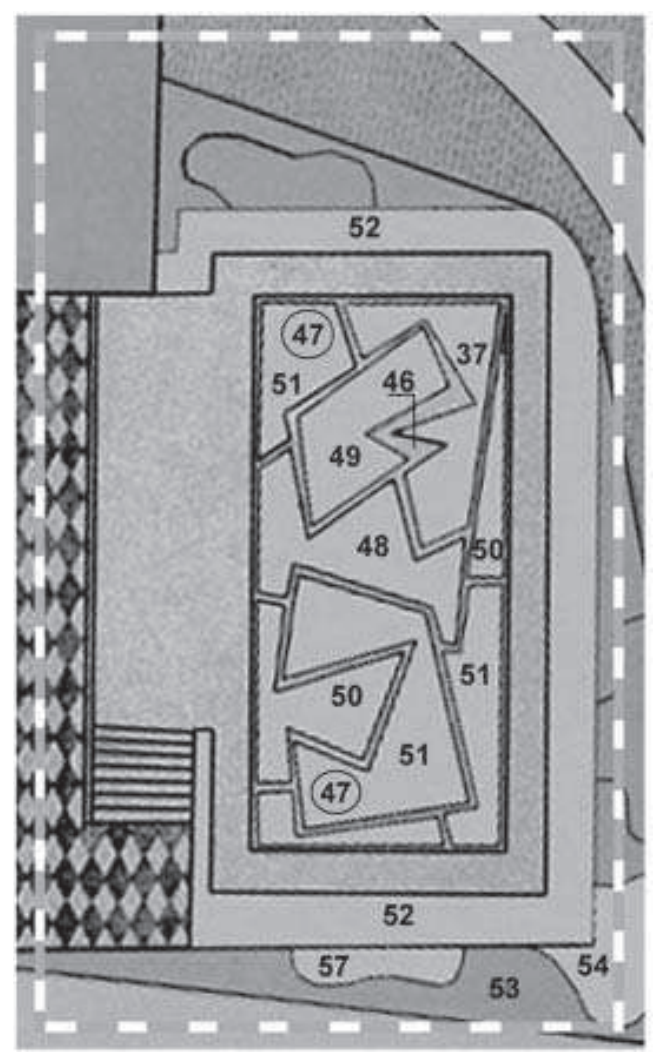

Figura 3: Jardim geométrico - Proposta de Burle Marx Fonte: Cópia trabalhada a partir do desenho em vegetal cedido por Isabel Duprat

\section{Listagem da vegetação proposta por Burle Marx para o jardim geométrico}

46. Buxus sempervirens

47. Coleus blumei Bent. (amarelo)

48. Coleus blumei Bent. (marrom alaranjado)

49. Coleus blumei Bent. (verde alface)

50. Hemigraphis colorata

51. Rhoeo discolor

52. Acalypha wilkesiana var. mosaica

53. Hypoestes sanguinolenta

54. Codiaeum variegatum

57. Philodendron selloum

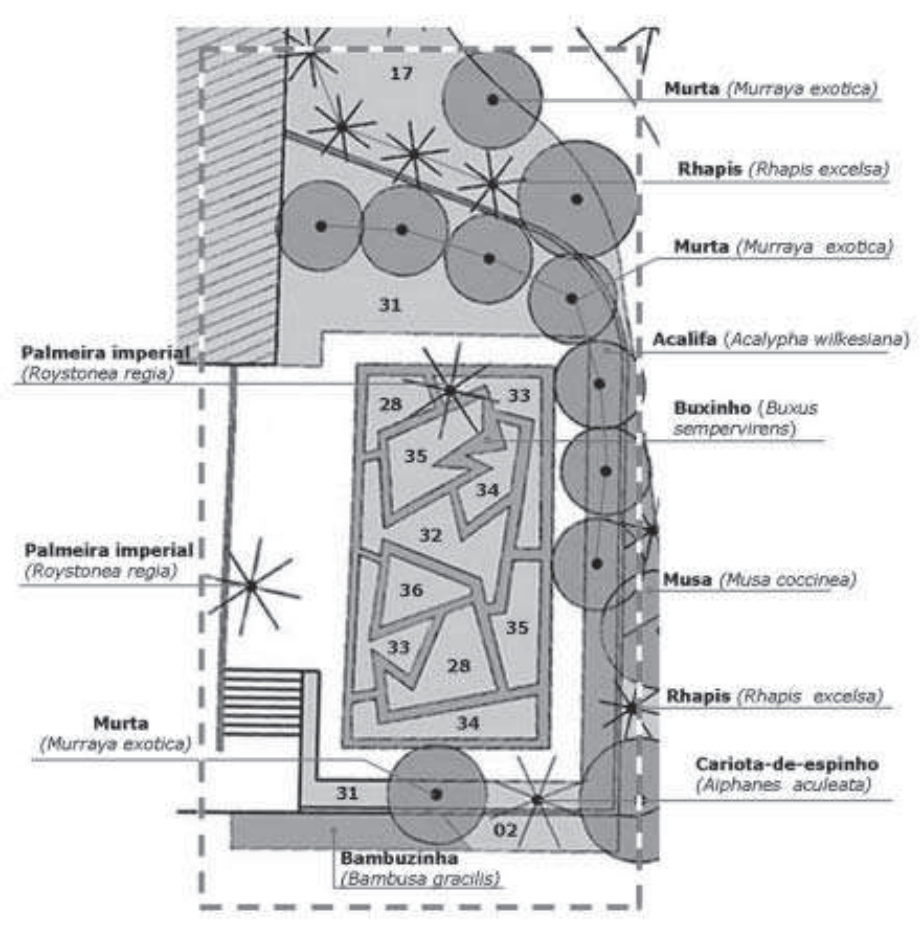

Figura 4: Jardim geométrico - Desenho indicativo das espécies vegetais, conforme aparecem no projeto de restauração dos jardins do Instituto Moreira Salles, de autoria de Isabel Duprat

Fonte: Cópia em vegetal cedida por Isabel Duprat (adaptada por Eloisa Santos).

\section{Listagem da vegetação de forração do jardim geométrico constante do projeto de recuperação de Isabel Duprat}

02. Pilea cadierei (Piléia)

17. Spathiphyllum cannaefolium (Lírio-da-paz)

28. Tradescantia Pallida (Setecresea)

31. Pilea nummularifolia (Dinheiro-em-penca)

32. Peristrophe angustifolia (Periquito-bambú)

33. Hemigraphis colorata (Hera-roxa)

34. Alternanthera dentada (Periquito-vermelho)

35. Alternanthera ficcoidea (Periquito-verde)

36. Duranta repens (Durantaamarela) 
A predominância do enviezamento das "aléias" na escala desse pequeno jardim, com a utilização de espécies vegetais tropicais de colorido intenso (como é o caso dos coleus e acalifas), e onde Burle Marx privilegiou a bi-dimensionalidade, reforça a configuração desse pequeno espaço como alegoria referenciada ao jardim geométrico francês. Porém, como a alegoria não caracteriza o Movimento Moderno, ao contrário do binômio forma / função, o jardim geométrico afastando-se desse cânone do modernismo apresenta-se apenas como um exercício lúdico do paisagista, de influência cubista. De certo modo, esse isolamento parece contrariar o critério estabelecido anteriormente, que considerou o jardim geométrico como "área" a ser destacada pelo diálogo que estabelece com a arquitetura, e poderíamos dizer que a coerência dessa escolha estaria justamente na negação de uma interação com ela. Por outro lado, se abandonarmos a idéia da alegoria, o jardim geométrico configura-se como manifestação do Modernismo, tal qual as experiências geométricas jardinistas de Paul Véra ${ }^{\mathrm{d}}$, sendo uma variação da transposição do pictórico cubista para o jardim, uma das marcas do repertório paisagístico de Burle Marx.

No projeto de restauração de Isabel Duprat o Jardim Geométrico aparece como "Jardim da Tenda", e, como podemos observar pela listagem da Fig.4, a vegetação do Projeto de Recuperação difere completamente daquela indicada por Burle Marx. Portanto, apenas a concepção formal foi preservada.

\section{Pátio Interno}

As diferenças entre o traçado dos canteiros, que aparecem no detalhe da prancha de que dispomos, e o que efetivamente foi realizado não impedem a apreensão da intenção de Roberto Burle Marx de tratar o Pátio Interno, para onde convergem a ala íntima e a área de estar e lazer, como espaço a ser transposto. A vegetação de maior porte, composta de Nolinas e Dracenas, que mesmo na fase adulta proporcionam a continuidade visual, contribui para essa integração espacial. Os canteiros contíguos ao piso do interior da edificação - em mármore, com padronagem em losangos branco rosado, e que avança para o exterior (fotos da Fig. 9) - reforçam o continuum espacial, e acentuam a incorporação dessa área ao interior da residência. Os vidros que o circundam conferem ao pátio a aparência de uma vitrine para exposição da vegetação.

A ausência de bancos, ou qualquer outro elemento que remeta à permanência, pontua a transitoriedade que também caracteriza o local. $\bigcirc$ piso do pátio em pedra portuguesa, na cor branca com detalhe central em rosa (Fig. 5), avança em direção à área da piscina, vista parcialmente daquele local.

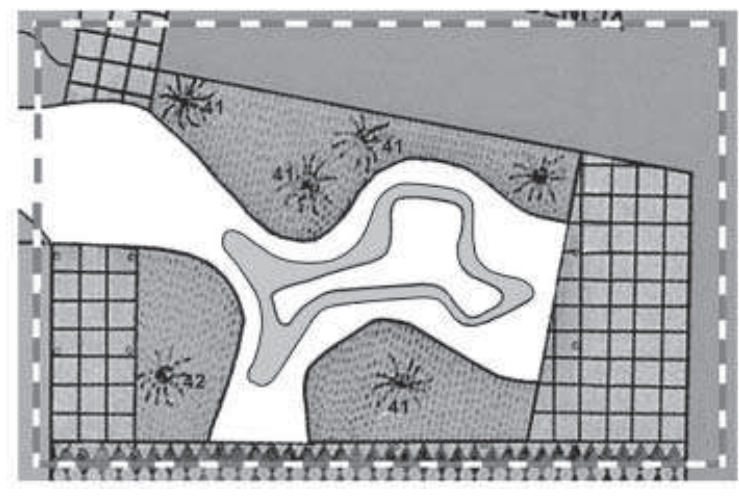

Figura 5: Pátio interno - Projeto de Burle Marx Fonte: Cópia do desenho cedida por Isabel Duprat, em 2003, colorida por Eloisa Santos para facilitar a leitura da proposta de Burle Marx

\section{Vegetação indicada para o pátio interno no projeto original}
41
- Beaucarnea recurvata (Nolina)
42 - Dracaena marginata

Obs.: essa prancha não apresenta indicação Do restante da vegetação. 


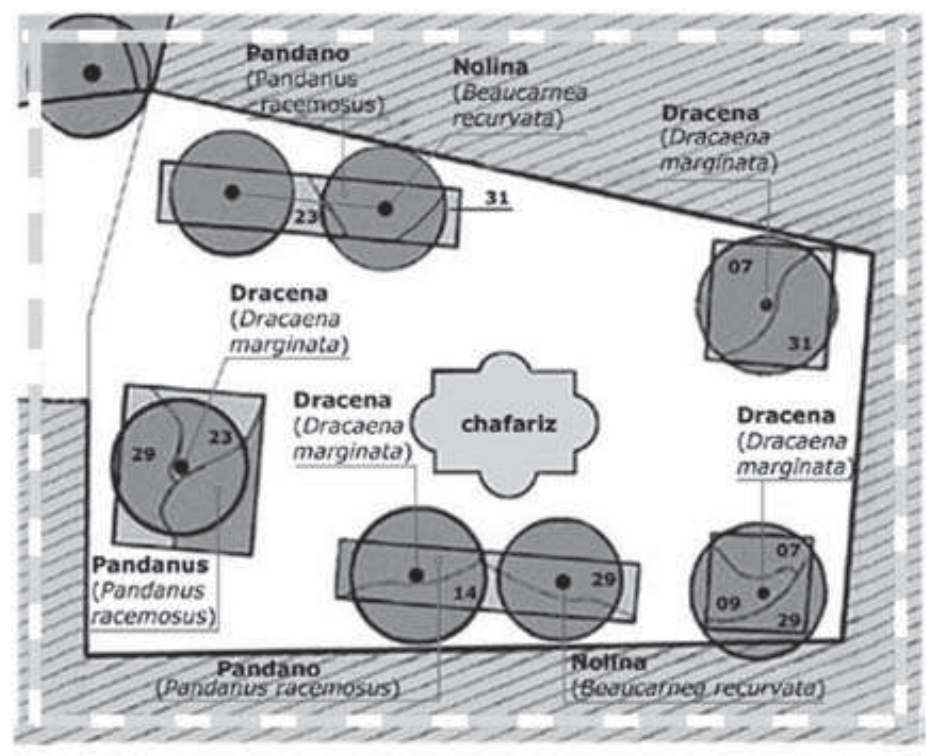

Figura 6: Pátio interno - Desenho assinalando as espécies vegetais constantes do projeto de restauração de Isabel Duprat

Fonte: Desenho elaborado por Eloisa Santos sobre cópia em vegetal do projeto cedida por Isabel Duprat
Listagem das plantas de forração utilizadas no Pátio Interno no

Projeto de Restauração

07. Philodendron martianum (Filodendro)

09. Ananas bracteatus (Ananás)

14. Davallia fejeensis (Rendaportuguesa)

20. Solenostemom scutellanoides (Coleus)

23. Sanseviera cylindrica (Sanseviera)

29. Cryptanthus bromelioides (Criptantus)

31. Pilea numularifolia (Dinheiro-em-penca)

O acréscimo do chafariz em estilo eclético ocorreu antes da intervenção da paisagista Isabel Duprat, assim como a troca do piso em pedra portuguesa pelo de lajota de pedra.

\section{Área da piscina}

O desenho de Burle Marx, que nos foi disponibilizado, indica três espelhos d'água para o local que denominamos Área da Piscina: a piscina, o lago que apresenta um painel de azulejos, e um pequeno lago em frente a um dos quartos da ala íntima da residência.

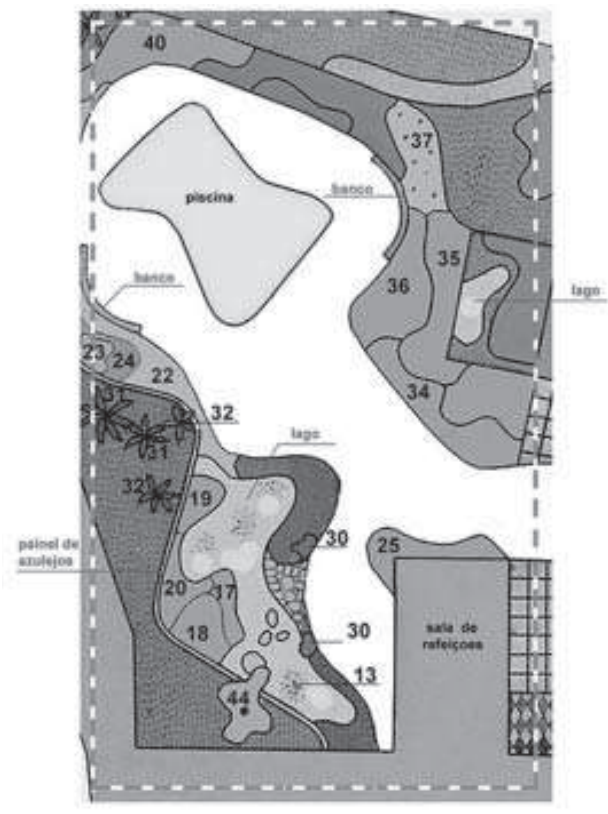

Figura 7: Área da piscina - Projeto de Burle Marx Fonte: Cópia trabalhada por Eloisa Santos a partir do desenho em vegetal cedido por Isabel Duprat

\section{Listagem da vegetação proposta para a àrea da piscina no projeto original}

$\begin{array}{ll}\begin{array}{l}\text { 13. Nymphaea ampla } \\ \text { rósea }\end{array} & \text { 30. Eragrostis curvula } \\ \text { 17. Lymnocharis flava } & \text { 31. Euterpe edulis } \\ \text { 18. Talia dealbata } & \text { 32. Euterpe oleracea } \\ \text { 19. Cyperus papyrus } & \text { 34. Moraea indioides } \\ \text { 20. Monthrichardia } & \text { 35. Petrea volubilis } \\ \text { linifera } & \text { 36. Coreopsis scandi- } \\ \text { 22. Hemerocalis flava } & \begin{array}{l}\text { folia } \\ \text { 37. Coleus blumei } \\ \text { (marrom) }\end{array} \\ \text { Roxbel. Musa coccinea } & \begin{array}{l}\text { 40. Canna indica } \\ \text { (larania) }\end{array} \\ \text { 24. Salvia splendens } & \begin{array}{l}\text { 44. Couroupita guia- } \\ \text { nensis }\end{array}\end{array}$


Observando as fotos dos jardins já implantados, concluímos que o desenho do qual dispomos, provavelmente, trata-se de um anteprojeto, e que, à semelhança do Pátio Interno, já analisado por nós, para que conseguíssemos uma razoável complementação daquelas indicações gráficas, fez-se necessário recorrer ao material fotográfico resultante de nossa pesquisa. No entanto, mesmo que sob essas condições, pudemos confirmar apenas a realização da piscina e do lago com o painel de azulejos.

Como visto anteriormente, essa área estava conectada ao Pátio Interno pelo piso em pedra portuguesa, que aqui se apresentava exclusivamente na cor branca, contornando a piscina e contornado quase inteiramente por um canteiro contínuo. A uniformidade desse piso pressupõe a neutralidade pretendida pelo paisagista para destaque dos elementos propostos. Estes funcionariam como figuras relacionadas às "paredes-fundo", constituídas pela vegetação de grande porte de todo o entorno - que, a princípio, é apreendida como um fundo verde uniforme.

A configuração dessa área como "fechada", resulta da relação entre sua dimensão e a altura dos elementos do entorno, compostos pelo morro próximo e pela vegetação de grande porte.

Para a parte de trás do painel, um elemento introduzido em alguns de seus projetos anteriores e em muitos do que se seguiram ${ }^{5}$, concebido aqui em azulejos, foram indicadas algumas palmeiras e uma árvore de grande porte - no anteprojeto aparece indicada a Abricó-de-macaco (Courupita guianensis) —, revelando que Burle Marx pretendia uma gradação de planos: o painel, a copa da vegetação e o morro.

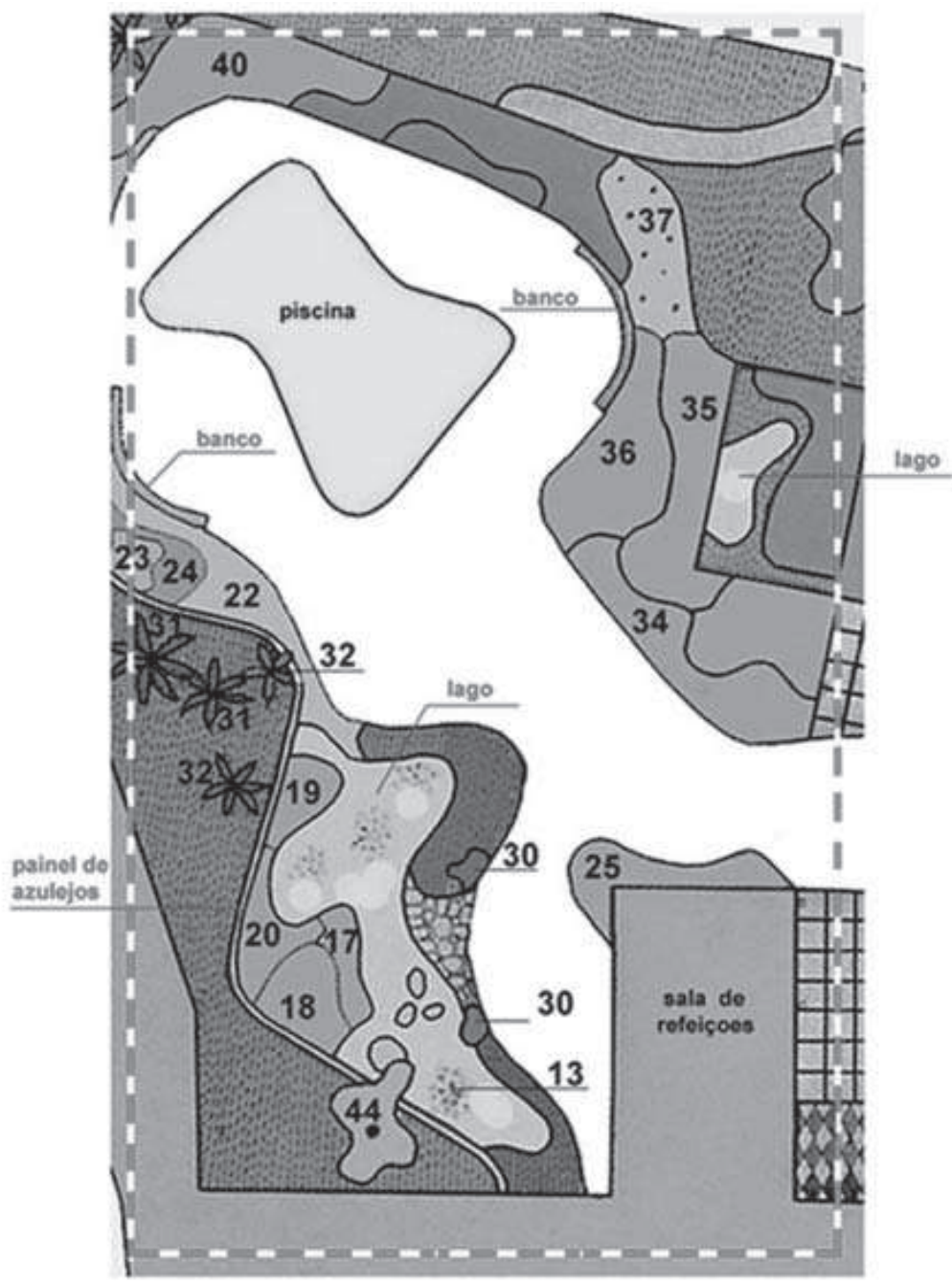

Figura 8: Área da piscina - Desenho indicativo das espécies vegetais, elaborado sobre o projeto de recuperação realizado por Isabel Duprat

Fonte: Cópia em vegetal do projeto cedida por Isabel Duprat e trabalhada por Eloisa Santos 


\section{Listagem das plantas de forração indicadas para a área da piscina no projeto de restauração}

\author{
03. Sanchezia nobilis (Sanquézia) \\ 11. Tradescantia zebrina (Zebrina) \\ 12. Axonopus compressus \\ (Grama-São Carlos) \\ 13. Adiantum raddianum (Avenca) \\ 14. Davallia fejeensis (Renda- \\ portuguesa) \\ 16. Canna indica (Canna) \\ 18. Dietes bicolor (Moréia- \\ amarela)
}

\author{
19. Dietes iridioides (Moréia-branca) \\ 21. Hemerocallis flava (Lírio-amarelo) \\ 22. Pennisetum setaceum (Capim-do- \\ Texas) \\ 23. Sanseviera cylindrica (Sanseviera) \\ 24. Wedelia paludosa (Vedélia) \\ 29. Cryptanthus bromelioides \\ (Criptantus) \\ 38. Coreopsis lanceolata \\ (Margaridinha-amarela)
}

A Dracena (Dracaena marginata) plantada à frente do painel - que não consta do anteprojeto, porém constatada em fotos da época - impede a apreensão da totalidade de sua composição.

A neutralidade do piso parece liberar a inclusão de um maior número de texturas - resultantes de um variado número de palmeiras, e árvores que apresentam troncos exuberantes (como o Pau-ferro), além de arbustos, massas arbustivas floríferas e forrações de coloração intensa. Em relação ao uso da vegetação, notamos que esta tende a esconder a arquitetura, cuja altura se harmoniza com a dimensão da Área da Piscina. Notamos uma recorrência desse procedimento nessa área, que resultou na acentuação da característica de fechamento desse espaço, e, na relação altura-dimensão, prevaleceu a primeira, proporcionada pelo entorno.

Quando Burle Marx esconde a parede de pedras, externa à sala de refeições, com a Macaranga (Macaranga grandifolia) e planta uma palmeira entouceirada (Areca Bambu) em frente a ela, cria uma abertura que, em relação à altura das laterais é menor que 1:1, o que leva o pedestre à curiosidade sobre o que encontraria ao transpô-la, revelando o elemento surpresa nesse tratamento paisagístico. Assim, o plano composto por piso e piscina funcionaria como uma clareira (v. foto à direita da Fig. 9).
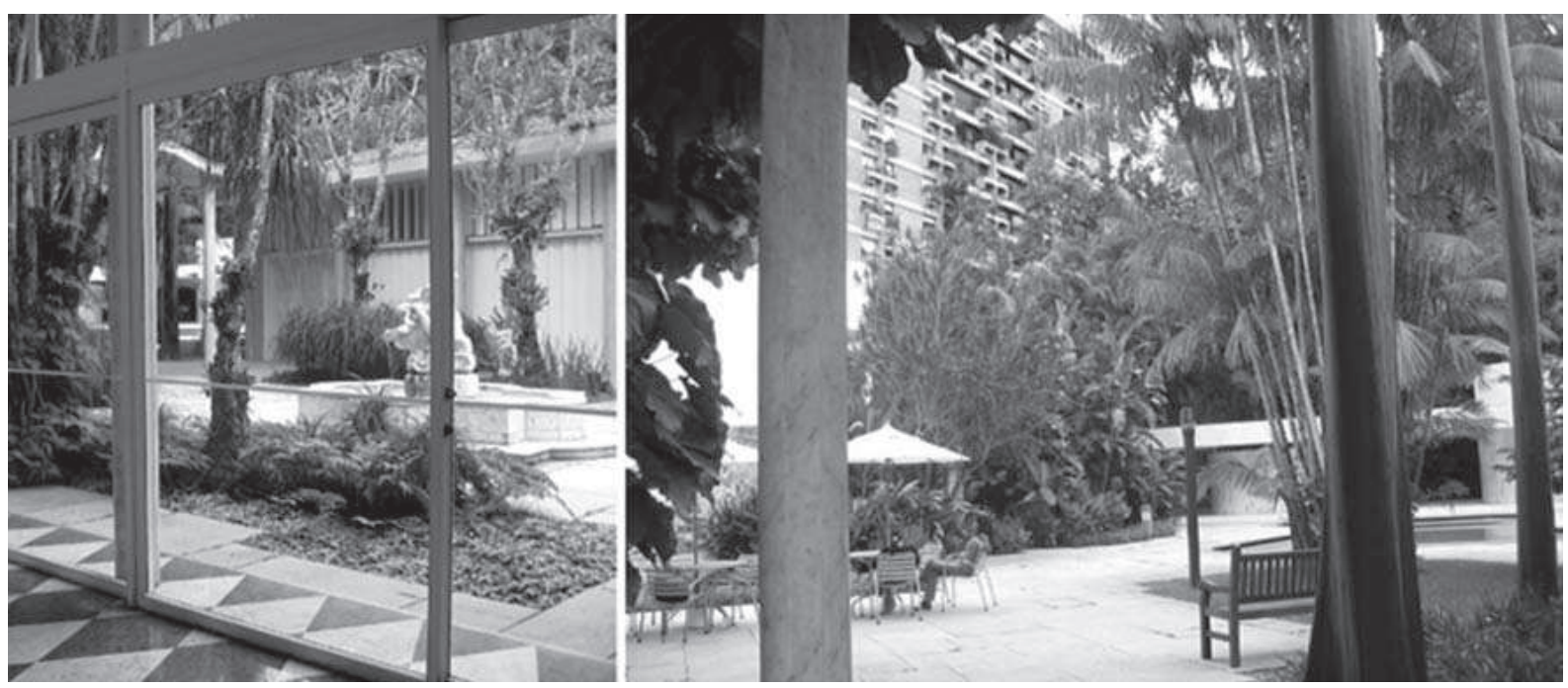

Figura 9: Pátio interno e área da piscina - Na foto à esquerda vemos o piso do interior avançando para o pátio interno. Na foto à direita observamos que o crescimento da vegetação e o surgimento do prédio à esquerda reforçaram a configuração do ambiente como um vale Crédito: Fotos de Eloísa Santos 
A intervenção de Isabel Duprat considerou uma série de adaptações arquitetônicas demandadas pela transformação do local, a partir de 1999, em uma instituição cultural privada. Decorridos quase cinqüenta anos da concepção original, destinada ao uso residencial, registramos algumas mudanças significativas - especialmente, no Pátio Interno e na Área da Piscina, onde o "fechamento" do espaço teve o reforço de alguns prédios de apartamentos surgidos na vizinhança.

\section{Modificações detectadas}

Dentre as modificações constatadas, registramos as mais significativas como interferência no espaço paisagístico:

\section{Área da piscina}

- O acréscimo do conjunto de instalações de sanitários e de vestiário. $\bigcirc$ volume desse pavilhão, que revela uma concepção arquitetônica diversa da que o arquiteto Olavo Redig de Campos adotou para a residência, impõe-se com grande destaque, em relação ao fundo composto por densa vegetação. Tal condição contraria a relação de integração entre a arquitetura e o espaço paisagístico, predominante até sua instalação.

- O piso da Área da Piscina, originalmente, era em pedra portuguesa branca, em continuidade ao piso do Pátio Interno, com os canteiros em contornos amebóides, conforme atestam as fotografias da época. Esse piso original foi trocado pelo de lajota de pedra, até o limite do pavilhão da piscina que apresenta o piso em mármore branco.

\section{Pátio interno}

- O acréscimo do chafariz em estilo eclético, com a escultura de um dragão, contrariou as linhas modernas da edificação;

- A mudança do piso original em pedra portuguesa branca para o de lajota de pedra. No projeto original, o desenho do piso do Pátio Interno, do qual dispomos, não indica as cores e nem o material empregado, porém, as fotos pesquisadas indicam que ali o piso era na cor clara. Como essa pedra se apresenta nas cores rosa, branco e preto, deduzimos que o desenho apresentado no material gráfico teria sido realizado nas cores rosa e branco.

Apesar de não termos analisado a área da fachada da ala íntima que dá para o Rio Rainha, observamos a eliminação do pequeno espelho d'água indicado no desenho de Burle Marx (v. Fig. 1). Porém, como parece tratar-se de um anteprojeto, conforme mencionado anteriormente, não podemos afirmar se, de fato, ele foi construído.

\section{Análise conclusiva}

Programa - residência unifamiliar de dimensões palacianas

- setorização das alas funcionais distintas no conjunto

Relação com o entorno - A existência dos morros e da pedra, o surgimento dos prédios vizinhos, o porte da vegetação nativa e da indicada nos projetos, caracterizam o espaço paisagístico como "fechado", semelhante a um vale, enfatizando o caráter da edificação privada e o da área de domínio particular.

236 Relação arquitetura $\mathrm{x}$ jardim - convém destacar primeiro o Pátio Interno, que teve seu condicionamento à concepção moderna de integração espaço interno x espaço externo, prejudicado pela inclusão do chafariz com a escultura em estilo eclético. 
O diálogo estabelecido entre a Área da piscina e o Pátio Interno, onde aparece a dicotomia espaço aberto $x$ espaço fechado, foi prejudicado pelas mudanças ocorridas no Pátio e pela edificação do Pavilhão da piscina.

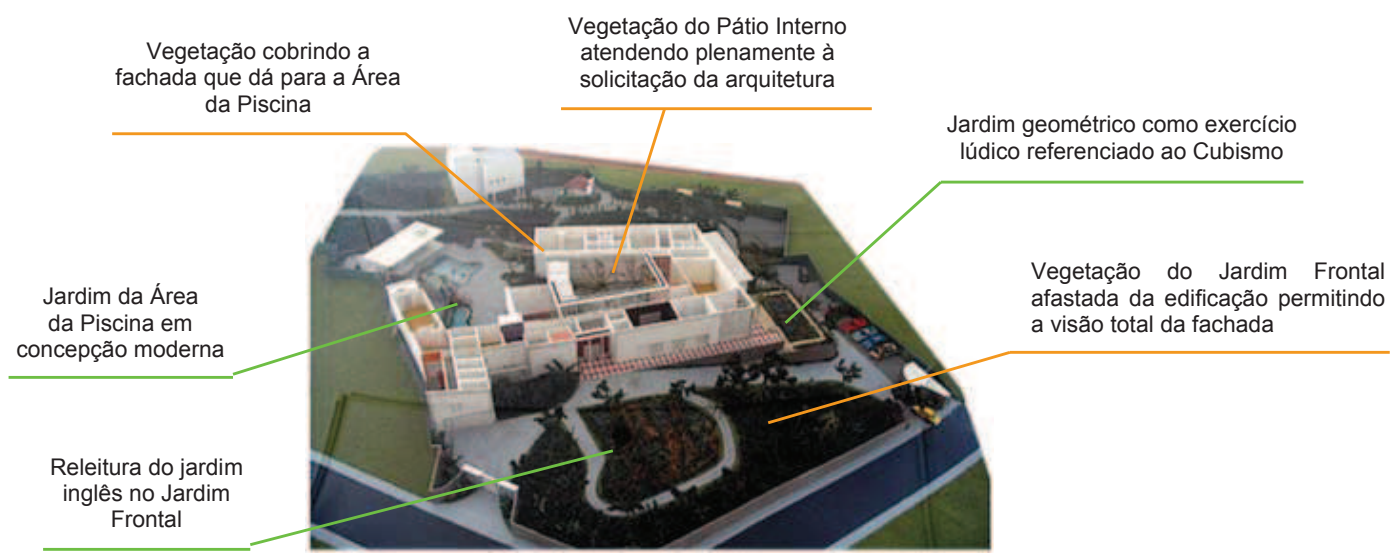

Figura 10: RELAÇÃO ARQUITETURA X JARDIM - A vegetação

diante do objeto arquitetônico e a concepção formal dos jardins.

Fonte: Imagens da maquete pertencente ao acervo do Instituto

Moreira Salles, em fotos da autora.

\section{Conclusão}

De modo geral, podemos dizer que na dialética que o paisagismo de Burle Marx estabelece com a arquitetura, sempre se apresenta a dicotomia entre movimento e inércia, traduzidos por configurações espaciais, tais como: permanência e passagem, opacidade e reflexão, permeabilidade e impermeabilidade, fechamento e abertura, continuidade e descontinuidade.

Dentro da diversidade apresentada pelos seus projetos, podemos destacar a recorrência do jogo de contrastes entre movimento e inércia e entre as linhas de sinuosidade e as linhas retas.

Na residência Moreira Salles, a forma sinuosa da piscina, do lago e do painel de azulejos, além da diversidade volumétrica, apresentada pela vegetação, imprimem movimento à espacialidade.

Ressaltamos também que os pisos em pedra portuguesa no Projeto Original foi uma recorrência em vários dos projetos de Burle Marx.

Em nossas pesquisas, observamos que em seus projetos as relações entre os volumes se apresentam diferenciadas, como no caso da Residência Moreira Salles - onde a vegetação estabelece relações volumétricas com a arquitetura, com interferências significativas na apreensão desta. $\mathrm{Na}$ área da piscina, as Arecas, os troncos do Pau-Mulato e a Macaranga fecham o espaço, formando uma "porta" nos dois sentidos - da residência em direção à área da piscina, e, no sentido contrário, quar Figura 10: Relação arquitetura $x$ jardim - A vegetação diante do objeto arquitetônico e a concepção formal

Com relação à compados jardins

val em diversos dos projetos

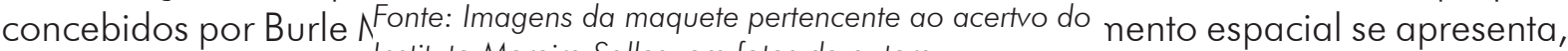
mesmo com a continulustituto Moreira Salles, em fotos da autora elementos construtivos adicionados à configuração atual, essa compartimentação tornou-se ainda mais acentuada.

Como em outros projetos, aqui também se faz presente o grafismo no tratamento do piso, revelando a modernidade dessa atuação paisagística, ao se constituir como transposição de manifestações pictóricas típicas da arte moderna. 
A autonomia de Burle Marx mostra-se maior em suas atuações para as edificações residenciais, contudo, sempre com a idéia de pertencimento ao conjunto formado pelo paisagismo e pela arquitetura, o que é constatado em seu procedimento os jardins para a Residência Moreira Salles.

Na consideração de que a sinuosidade dos canteiros de Burle Marx, a marca de sua atuação, seria a fusão de duas fontes antitéticas - os jardins de Capability Brown ${ }^{\text {to }}$ e as manifestações plásticas do modernismo - , no Jardim Frontal e na Área da Piscina ela se faz presente. Essa ocorrência em Burle Marx insere-se num intercâmbio intenso com a arquitetura, que, na maioria dos casos, é colocada em evidência no contraste entre o movimento de seus jardins e a inércia e a geometrização das edificações.

Em fase de diagnóstico, conforme relato de Isabel Duprat ${ }^{97}$ :

[...] o jardim evidenciou sua composição por áreas com características bastante diferenciadas e que foram tratadas segundo posturas de intervenção também bastante específicas:

- Áreas com projeto e tratamento paisagístico de autoria de Roberto Burle Marx, com limite às margens do Rio Rainha;

- Áreas que se mantiveram em seu estado natural com acréscimo posterior de outras espécies;

- Áreas novas criadas pelo projeto de restauração e adaptação da casa.

O projeto de recuperação dos jardins, ainda segundo Duprat, considerou a plena integração entre o paisagismo e a arquitetura.

\section{Notas}

(1) Coincidentemente, constatamos que no livro de Vera Beatriz Siqueira sobre Roberto Burle Marx, editado em 2001, a historiadora escolhera apenas esse desenho, dentre uma série de outros elaborados pelo paisagista, segundo relato da autora, para ilustrar o projeto de paisagismo para a residência Moreira Salles.

(2) Conforme informação de Isabel Duprat em Os jardins do Instituto Moreira Salles no Rio de Janeiro. In Notícias da ABAP (Boletim Mensal), Ano 2, n5, janeiro de 2000.

(3) As referências à distribuição dos cômodos da residência em "alas" não anulam o entendimento que temos da edificação como volume unitário.

(4) Entre 1925 e 1926, os paisagistas André e Paul Véra, quando requisitados para colocarem em prática o que entendiam como vanguarda na área do paisagismo, criaram os jardins de uma das propriedades do Visconde de Noailles, na França.

(5) Anteriormente ao criado para a Residência Moreira Salles, Burle Marx realizou os seguintes painéis: em 1947, na Residência Jean Marie Diest e no Instituto Oswaldo Cruz, ambos no Rio de Janeiro; em 1948, na Residência Arnaldo Aizim, para projeto arquitetônico de Paulo Santos, também no Rio de Janeiro: em 1950, na Residência Olivo Gomes, para projeto arquitetônico de Rino Levi e Roberto de Cerqueira César, em São José dos Campos, São Paulo.

(6) Lancelot "Capability" BROWN - (1716-1783). Paisagista inglês, que atuou por mais de três décadas de forma tão intensa, cuja produção sem paralelo, pela quantidade e pela escala, marcou a história do paisagismo europeu.

(7) "Os jardins do Instituto Moreira Salles no Rio de Janeiro". Notícias da ABAP (Boletim Mensal), Ano 2, n 5, jan/2000.

\section{Bibliografia}

DUPRAT, Isabel. Os jardins do Instituto Moreira Salles no Rio de Janeiro. Notícias da ABAP, boletim mensal, ano 2, n. 5, 2000.

SANTOS, Eloísa. Burle Marx e a arquitetura moderna. 2004. Dissertação (Mestrado) - PROARQ-FAU/UFRJ, Rio de Janeiro, 2004.

SIQUEIRA, Vera Beatriz. BURLE MARX. São Paulo: Cosac \& Naif, 2001. 